\title{
Preparation of electrochemical sensor based on $\beta$ - cyclodextrin/Carbon Nanotube Nanocomposite for Donepezil Hydrochloride as drug for treatment of Alzheimer's Disease
}

\author{
Qiong Qin ${ }^{1}$, Xin Wang ${ }^{1}$, Jincui Shi ${ }^{1}$, Danfeng $W u^{2, *}$ \\ ${ }^{1}$ Psychiatry Department, Wuhan Youfu Hospital, Wuhan, 430023, China \\ ${ }^{2}$ Orthopaedics, Fifth Hospital in Wuhan, Wuhan, 430050, China \\ *E-mail: wdf3091@sina.com
}

Received: 5 September 2021 / Accepted: 27 October 2021 / Published: 6 December 2021

\begin{abstract}
This study was conducted to prepare nanocomposite based carbon nanotubes (CNTs) and $\beta$ cyclodextrin-CNTs ( $\beta C D$-CNTs) as an electrochemical sensor for determination of DNP as medicine for treatment of Alzheimer's disease. The electrodepositon method was used for modification of the glassy carbon electrode (GCE) surface with a nanocomposite of $\beta C D-C N T s$. The structural analyses of electrodeposited $\beta C D-C N T$ s on the GCE surface using SEM and XRD revealed that $\beta C D$ particles covered the high porous bundles of entangled CNTs surface and created of a highly cross-linked CNTs composite. The electrochemical characterizations using CV and DPV techniques showed the synergetic effect of CNTs and $\beta C D$ molecules can improve the response of nanocomposite modified GCE to determine the DNP. Results showed that the response of $\beta C D-C N T s / G C E$ was sensitive, selective and stable to determination of the DNP, and linear range, sensitivity, and limit of detection were obtained at 0 to $550 \mu \mathrm{M}, 0.03233 \mu \mathrm{A} / \mu \mathrm{M}$ and $8.5 \mathrm{nM}$, respectively. In prepared pharmaceutical samples of Aricept tablets, the precision and applicability of the $\beta \mathrm{CD}$-CNTs/GCE for DNP determination sensor were evaluated, and the results showed that acceptable recovery (91.00 to 98.50\%) and RSD (3.84 to 4.61\%) values were obtained, as well as the appropriate performance of the $\beta C D-C N T s / G C E$ for DNP determination sensor in clinical applications.
\end{abstract}

Keywords: CNTs; $\beta$-cyclodextrin; Nanocomposite; Electrodepositon; Donepezil hydrochloride; Differential pulse voltammetry

\section{FULL TEXT}

(C) 2022 The Authors. Published by ESG (www.electrochemsci.org). This article is an open access article distributed under the terms and conditions of the Creative Commons Attribution license (http://creativecommons.org/licenses/by/4.0/). 